
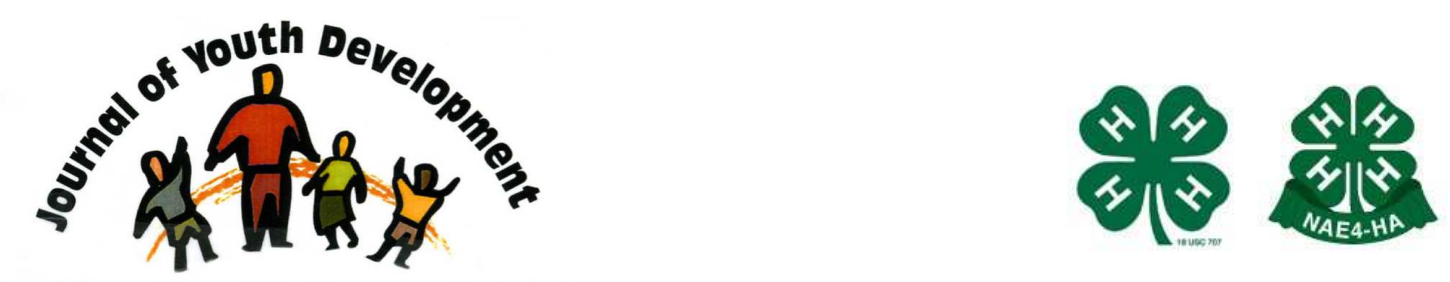

Bridging Research \& Practice

\title{
Qualitative Outcomes of Participation in Fishing Components of NOLS Courses
}

\author{
Katherine Soule \\ Recreation, Parks \& Tourism Administration \\ California Polytechnic State University \\ San Luis Obispo,CA \\ kesoule@gmail.com \\ Marni Goldenberg \\ Recreation, Parks \& Tourism Administration \\ California Polytechnic State University \\ San Luis Obispo,CA \\ mgoldenb@calpoly.edu
}




\title{
JOURNAL OF YOUTH DEVELOPMENT \\ bridging research and practice

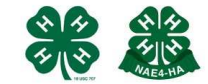

Volume 7, Number 1, Spring 2012

Article 120701FA005

\section{Qualitative Outcomes of Participation in Fishing Components of NOLS Courses}

Katherine Soule and Marni Goldenberg

California Polytechnic State University

\begin{abstract}
Numerous fishing education programs in the United States strive to impart hard skill development, as well as life values to youth. This study employs utilizing semi-structured interviewing techniques and means-end analysis to evaluate the effects of youth participation in fishing components of NOLS courses. Interviews were conducted over five years to study benefit retention across time. The fishing component led to thirteen consequences, most frequently to youth feeling a sense of fun and excitement, developing hard skills, and having a new experience/opportunity. In turn, these consequences led youth to a number of values, including transference of information learned or benefits to other areas of their lives, an increased self-respect/esteem/ confidence, self-fulfillment, a sense of accomplishment, and selfawareness. These results provide educators and program managers with information to direct programming development for youth attainment and retention of specific participation outcomes.
\end{abstract}

\section{Introduction}

In the United States, fishing is a popular recreational past-time. According to the U.S. Fish \& Wildlife Service, one of every eight Americans fished in 2006, including 9.4 million youths aged 6-17 (USDI, 2006). The majority of these anglers were male (75\%) and residents of metropolitan areas (73\%). Freshwater fishing is the most popular form of fishing in the country, where anglers fish for black bass, pan fish, catfish, trout, crappie, and white bass (USDI, 2006).

This paper will highlight research which examined how participation in the fishing component of National Outdoor Leadership School (NOLS) courses affects youths' lives through analysis of connections between consequences of participation and value attainment. Initial data collection occurred at a NOLS program site in the Wind River Mountains of Wyoming during the summer of 2006. Follow-up telephone interviews were conducted with original study participants during 2007, 2008, 2009, and 2010. In utilizing a longitudinal approach, researchers studied how 
participant outcomes may have persisted four years after course participation. Researchers utilized means-end theory, which links the experience of fishing (the means) with the personal values of an individual youth participant (the ends). The fishing experience led directly to consequences, such as having fun, interacting with others, and hard skill development. These consequences led to values, which are an individual's desired end-state of mind, such as gaining self-respect/esteem/confidence, developing warm relationships with others, or having a sense of accomplishment.

\section{Purpose Statement}

The purpose of this study was to gain a better understanding of the outcomes (consequences and values) that youth experienced from participation in the fishing components of a NOLS wilderness adventure program. Additionally, the study considered the effects these outcomes have on participants' lives up to four years after course completion. This study sought to answer the following research questions:

1) What are the consequences and values of youth participation in the fishing component of NOLS courses?

2) Do youth outcomes associated with participation in the fishing component of NOLS courses endure 4 years after course completion?

\section{Literature Review}

This literature review looks at outcomes of participation in recreational fishing, as well as examining prior studies of fishing education program outcomes.

\section{Recreational Fishing}

Studies on recreational fishing have found that angler participation and satisfaction is related to enjoyment of the experience, setting, and related social interactions (Arlinghaus, 2006; Fair, 2006; Holland \& Ditton, 1992; Spencer, 1993). Holland and Ditton (1992) analyzed how 166 anglers rated fishing satisfaction dimensions. They discovered that the most important dimensions were "enjoying a quality environment" and "feeling a sense of freedom." In this study, only $6 \%$ of the anglers felt that catching fish was the most important dimension for satisfaction. Spencer (1993) found that angler satisfaction on a lake in MN was related to fishing success, fish species, and angler residency. Additionally, he found that anglers were motivated to participate in a fishing experience for more than just the catch, as their motivations were related to being outdoors, participating in an interactive experience, and social factors.

In a more recent study, Fair (2006) examined the effects of participation in a substance abuse recovery camp through in-depth interviews. The camp's programming utilized fishing as a means to promote healing and self-sufficiency. She found that many participants enjoyed fishing and found it to be good therapy, which provided a way "to work out their frustration and grief" (p. 122). Arlinghaus (2006) found that the majority of participants (89.5\%) agreed with the statement that "a fishing trip can be successful to me, even if no fish are caught" (p. 598). These study participants indicated that non-catch aspects of the fishing experience, such as relaxation, being outside by the water, and enjoying the company, played a strong part in their motivation to go fishing, as well as their satisfaction. Important non-catch aspects studied included: "relaxing in the outdoors at the water side," "fishing in pleasant company," "experiencing a natural setting," and "enjoying clear water." In reviewing prior research results, 
Floyd, Nicholas, Lee, Lee, and Scott (2006) found that recreational fishing provides participants with a variety of social benefits, relaxation, and an opportunity to enjoy nature.

\section{Fishing Education Programs}

Throughout the United States, there are many educational programs and groups that strive to impart the benefits of recreational fishing to youth through hard skill development, opportunity provision, and group community. Such opportunities are so important to youth development that the State of California has deemed that "Catch a Fish" be a right of childhood passage, which is included in California's Children's Outdoor Bill of Rights (California Roundtable on Recreation, Parks and Tourism, 2004). Prior research provides insight into the outcomes of participating in fishing components of outdoor education programs, such as Hooked on Fishing, Not on Drugs or the New York State Sportfishing, and Aquatic Resources Education Program. Results from prior studies suggest that youth participants developed hard skills, feel excitement about and enjoyment for fishing, and have a desire to fish again in the future (Flowers, 2010; Koupal \& Krasny, 2003; Palmberg \& Kuru, 2000; Siemer \& Knuth, 2001).

Researchers often found that despite program objectives, participation did not increase youths' sense of environmental stewardship compared to pre-studies or control populations (Flowers, 2010; Koupal \& Krasny, 2003; Siemer \& Knuth, 2001). Based on study results, Siemer and Knuth (2001) recommended further research to determine the specific effects of program participation rather than prior fishing experience. Flowers (2010) emphasized the importance of continued program evaluations and studies to determine if programming objectives are being met. Additionally, numerous researchers cited a need for longitudinal studies to evaluate program effectiveness and participation outcomes for boating, fishing, and stewardship education programs that "increase participation in fishing and boating as well as the stewardship of the aquatic and marine resources that support these activities" (Fedler, 2001, p.1).

\section{Methods}

Data were collected from participants who completed NOLS courses in Wyoming's Wind River Mountains during summer of 2006. Participants came from 40 different NOLS courses that were fourteen days or longer, co-ed, and designed for students aged 14 years and older. In 2006, 281 youth participants aged 14-21 provided contact information to be included in annual followup studies through 2010. These students were contacted through a convenience sampling method as the courses came together at a program site near Lander, Wyoming and their participation was voluntary. Information collected included: age, gender, ethnicity, prior NOLS involvement, telephone number(s), mailing address(es), and email address(es).

Follow-up interviews were conducted in 2007, 2008, 2009, and 2010. Each year, all original youth participants were called but some were unreachable as their contact information had been changed or they opted to no longer participate. During these follow-up data collections, subjects participated in phone interviews that were completed based on the convenience of the participants. Participants were asked to provide their current age, email address(es), occupation, and whether they would recommend an NOLS program to people they know. Participants were also asked to remember three or four of the most meaningful components or experiences from their course. Once the participants provided their responses, they were asked a series of questions using the laddering technique for each component or experience they mentioned. 
Using the laddering technique, researchers asked participants a series of open-ended questions. First, they asked participants to remember three or four attributes (or course components) from their NOLS experiences. The respondent was then asked why that attribute was important. After the participants responded, researchers asked again, "why is that important?" This process of asking, "Why is that important?" continued for each response given until the respondent could no longer provide a meaningful answer. This interview technique moves respondents up the "ladder of abstraction," linking the concrete course attributes they identified with the more abstract consequences and personal values. Through this line of questioning, participants were asked about each of the attributes they identified at the beginning of the interview. Ladders were coded with content codes and entered into the LadderMap computer program. The content codes were analyzed by an independent coder to determine intercoder reliability.

Participants were not asked to speak about fishing in particular and only mentioned the attribute if they felt that it was one of the most important aspects of their NOLS experience. During data analysis, researchers noticed that while fishing was not one of the most frequently mentioned attributes, some youth participants consistently cited fishing as one of the most important aspects of their NOLS course during annual follow-up data collections. This research focuses on those ladders associated with the attribute fishing. An implication matrix was created to assess the number of times fishing was linked with other concepts and a hierarchical value map (HVM) was created as a visual representation of the data. Researchers also used transcriptions from telephone interviews and interview scripts to identify meaningful quotes from youth interviews related to fishing components of NOLS courses.

\section{Results}

During the course of data collection, 38 participants (13.5\%) identified fishing as one of the three most meaningful attributes of their NOLS course. Over the course of the five years study, these 38 participants mentioned the attribute fishing in 46 separate ladders. The majority of the youth (14-21 years old) that mentioned fishing were male (89.5\%). While all ladders moved from the attribute level to consequences and values, some participants spoke mainly about the catch itself. One male explained that fishing was important to him because "It was just the best fishing from the whole time...I love fishing, and the fact that every single cast was a catch, and the fact that every single fish was from my fingertip to my elbow...I don't know, it was just great fishing." On the HVM, the attribute fishing led to thirteen consequences and seven values (see Figure 1). 
Figure 1

Hierarchical Value Map for All Subjects ( $N=38)$, cut-off value of 2 ( $84 \%$ of data)

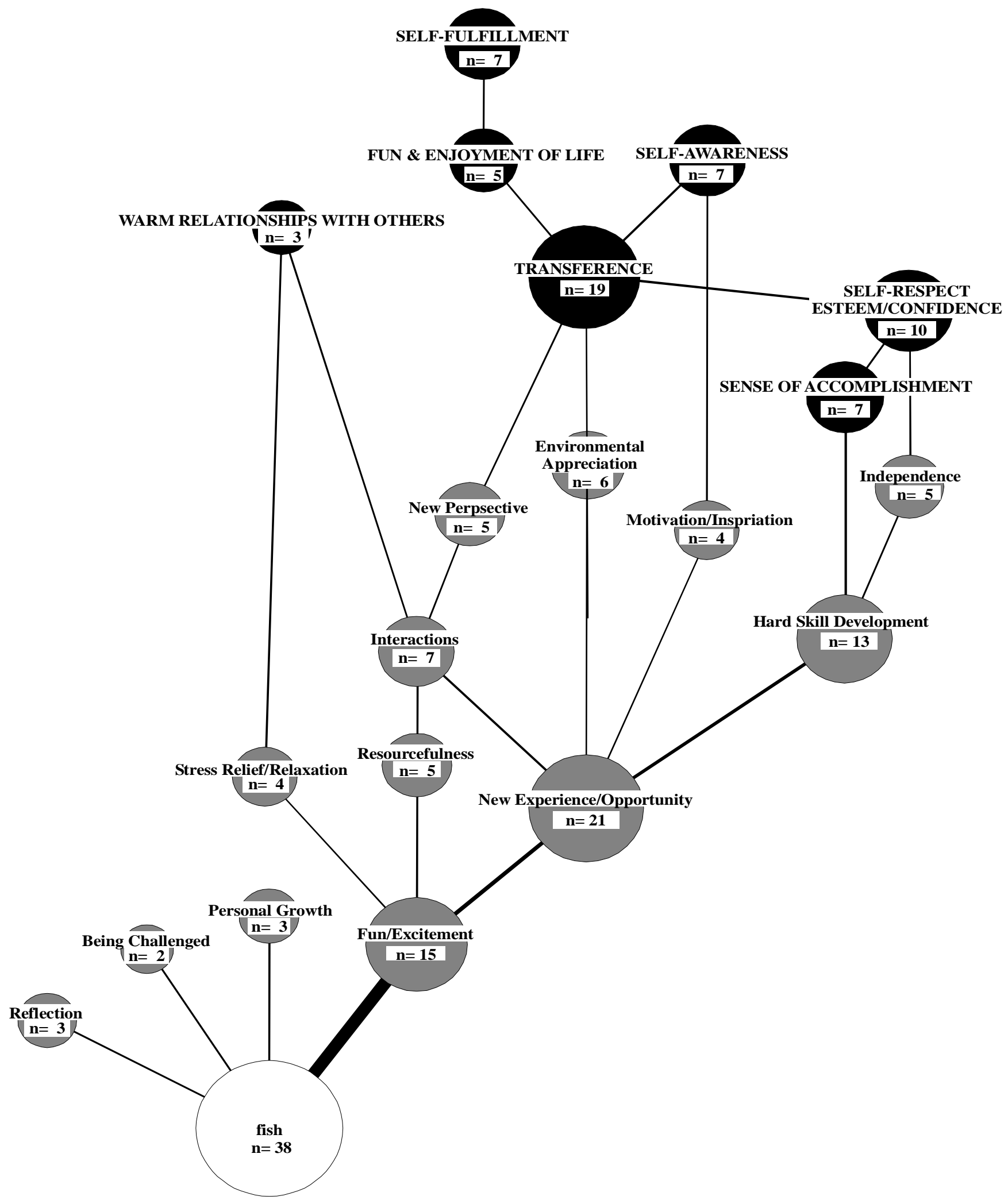




\section{Consequences}

Fishing led to 13 consequences. The most frequently mentioned consequences included: new experience/opportunity, fun/excitement, and hard skill development.

\section{New Experience/Opportunity.}

Fishing led to the consequence new experience/opportunity 21 times in 46 ladders (45.7\%). In many cases, fishing on the NOLS course was a new experience for participants, who had never caught a fish before. These youth described the opportunity to try fishing as "really spectacular," and "a unique experience for me." One male youth explained "it was just cool coming from a prep school going into a totally different situation... It takes me out of my bubble, that I was in, in prep school and life at home." Another said "I had never done anything like that...I just had never umm been in an environment where I had the ability to have fishing pole..."

\section{Fun/Excitement.}

Fishing led to the consequence fun/excitement 15 times (32.6\%). Participants reported that fishing caused them to experience a sense of fun or enjoyment. One male participant explained "I don't eat fish but fly fishing was still really enjoyable... something about just casting just back and forth, it's, it's just really calming and it's great to just be on the side of a river or a small lake and you're just enjoying being out there and you don't really care if you catch food. But aside from that, it's just a really, really fun experience to be able to relax and take a step away."

\section{Hard Skill Development.}

Fishing led to the consequence hard skill development 12 times (26.1\%). For participants who had fished previously, their experience allowed them to practice and improve their skills. One participant explained that "I love fishing. When I was younger I used to fish with my dad all the time and I had never tried fly fishing... so it was interesting to practice that and actually catch some." Another said learning was important to him because "I had barely even been able to catch fish before." Others talked about not only learning how to catch a fish but also how to prepare it for consumption. One explained "it's cool to take food from the wild and work on the outdoor cooking skills."

\section{Values}

Completing the "ladder of abstraction," fishing was associated with seven values, most frequently: transference, self-respect/esteem/confidence, self-fulfillment, self-awareness, and sense of accomplishment.

\section{Transference.}

Means-end chains associated with fishing led to the value transference 19 times (41.3\%). Youth frequently reported transferring the consequences of participating in fishing to their life outside of NOLS. Participants explained that they continue to use the hard skills that they developed by continuing to fish. Four years after course completion, one participant commented "I enjoy fishing, and hunting, and being outdoors." Another youth transferred the feelings of independence that he obtained when learning to fish, saying that "it's important to be independent and be able to take care of yourself. Wherever you go, you are going to face challenges and you need to be prepared for them." 
Self-Respect/Esteem/Confidence.

Means-end chains associated with fishing led to the value self-respect/esteem/confidence ten times (89.8\%). One participant explained that "I guess just like knowing...that I like had a role and was...proficient in fulfilling of what others expected of me..." Fishing and the opportunity to provide dinner for themselves and group members increased youth's self-esteem and gave them more confidence in their abilities.

\section{Self-Fulfillment.}

Means-end chains associated with fishing led to the value self-fulfillment seven times (15.2\%). A number of youth that identified fishing as one of the most important aspects of their NOLS course specifically joined the course to fish. One male explained that fishing during the course was important to him because it "was kind of one of the main reasons I did the course, it was definitely one of the things that attracted me to it, that particular course of NOLS." Such youth were able to experience a sense of self-fulfillment when their desire to fish in Wyoming was met.

\section{Sense of Accomplishment.}

Means-end chains associated with fishing led to the value of sense of accomplishment seven times (15.2\%). Several participants experienced a sense of accomplishment from the catch itself, especially when obtaining personal goals or "catching a lot of fish." Other youth mentioned the feeling of providing dinner for themselves and their group members. One female said "It was just me and this other girl kinda standing out in the middle of this lake...trying to catch a fish and she caught one and you know that was our dinner for the night. The guys cooked it... it felt good." Another male participant explained "There was one time when we ran out of food and uh I was the only one who was able to fly fish well and like I was able to catch fish and we were able to eat dinner and that was pretty cool."

\section{Self-Awareness.}

Means-end chains associated with fishing led to the value self-awareness seven times (15.2\%). One male participant said "having that control over your food and your life was, was nice. It was nice to have that control, you know... Especially as a teenager, you know, especially because I guess when you're going through what everyone goes through as a teenager, uh, kind of, umm, it's really important, important to realize that you can control your own destiny, your own life, you own hands."

\section{Discussion}

These results demonstrate similar benefits of recreational fishing and participation in fishing education as prior research. Multiple studies have shown that youth continue to have an interest in fishing after completing an educational course (Flowers, 2010; Holland \& Ditton, 1992; Koupal \& Krasny, 2003; Palmberg \& Kuru, 2000; Siemer \& Knuth, 2001). This research demonstrates that fishing education provides youth with the ability and desire to continue fishing after course completion. Numerous researchers have reported that enjoyment of the experience impacts angler motivations, as well as satisfaction (Arlinghaus, 2006; Flowers, 2010; Holland \& Ditton, 1992; Koupal \& Krasny, 2003; Palmberg \& Kuru, 2000; Siemer \& Knuth, 2001). Similarly, the youth participants in this study frequently reported that they enjoyed their fishing experiences, mentioning that fishing was "a good time," "fun," "really nice," and "my favorite part." Fishing components of outdoor education programs provide youth with a similar sense of independence and freedom that is associated with recreational fishing populations (Holland \& Ditton, 1992). 
Additionally, these results validate previous studies that found that despite programing objectives, participation in fishing education does not increase participants' sense of environmental stewardship or effect their behavior towards environmental concerns (Flowers, 2010; Koupal \& Krasny, 2003; Siemer \& Knuth, 2001). In this study, the attribute fishing did not lead to the consequence environmental appreciation or the transference of knowledge gained in order to protect the environment, which indicates that participation in fishing components of their NOLS course did not cause participants to have an increased sense of environmental stewardship.

This study meets research needs identified in prior studies. Siemer and Knuth (2001) cited the need to study specifically how program participation effects youth. By examining the ladders associated with the fishing attribute, this study investigated how participation in the fishing components of NOLS courses impacted youth outcomes. Numerous researchers called for longitudinal studies that measure the effects and impacts of course participation over time (Felder, 2001). This study presented data collected over five years, following participant outcomes from immediately after course completion to four years later, which demonstrates that participation in fishing education can have a meaningful and lasting impact on youth.

\section{Managerial Implications}

The results of this study provide some insight into the lessons and benefits that youth transfer from participation in fishing education into other areas of their lives, as well as the personal values that have an effect in youths' lives years after participation. Managers can use this information during program marketing and when attempting to obtain program funding. For programs that cite objectives aimed at improving youth lives, this research suggests that such objectives are valid as fishing education increases youth's self-respect/esteem/confidence, provides a sense of self-fulfillment and self-awareness, and offers transferable lessons and benefits. To facilitate the attainment of these values, program managers should strive to deliver opportunities that lead to these values by cultivating a sense of fun and excitement, teaching hard skills, and providing new experiences for youth anglers.

\section{Research Implications}

The sample population for data in this research was limited to youth who said that fishing was one of the three most important attributes of their NOLS course experience. Future research could conduct in-depth interviews with a larger population of youth to see if the fishing component affected all participants in a similar manner. A comparison between outcomes of participation in NOLS fishing courses versus NOLS general courses with fishing attributes may provide additional insight into youth outcomes. Researchers may also consider researching other outcomes of participation in other outdoor adventure education programs with fishing components. Females were limited in this sample population, future research should include a greater number of female youth and could examine differences in outcomes by gender.

\section{Limitations}

Limitations of this study include: sampling based on a convenience sample, a small sample population, and data being condensed when entered into LadderMap. Several participants were unreachable four years after the initial data collection due to moving, conflicting schedules, or change of contact information. A final limitation of the study was the lack of consideration for 
other factors that could affect participant outcomes, such as program philosophy, weather factors, or course instructors. While program philosophy has an effect on participant outcomes, the study was not designed to measure this.

\section{Acknowledgements}

The researchers would like to thank the California State Agriculture Research Initiative and a USDA McIntire-Stennis Grant for their financial support, as well as, the National Outdoor Leadership School for assistance in reaching subjects and providing background information.

\section{References}

Arlinghaus, R. (2006). On the apparently striking disconnect between motivation and satisfaction in recreational fishing: The case of catch oriented German anglers. North American Journal of Fisheries Management, 26, 592-605.

California Roundtable on Recreation, Parks, and Tourism. (2004). California children's outdoor bill of rights. Sacramento, CA. Retrieved September 9, 2009, from http://www.calroundtable.org/files/cobr_edit.pdf

Fair, M. (2006). The relationship of the transformative learning experience on substance abuse treatment outcomes: The Hudson Lake Recovery Camp curriculum. Proceedings of the 47th Annual Adult Education Research Conference, 118-123.

Fedler, A.J. (Ed.). (2001). Defining Best Practices in Boating, Fishing, and Stewardship Education. Prepared for the Recreational Boating and Fishing Foundation under Contract \#RPFF-00-C-004.

Flowers, A.B. (2010). Blazing an evaluation pathway: Lessons learned from applying utilizationfocused evaluation to a conservation education program. Evaluation and Program Planning, $33(2), 165-171$.

Floyd, M.F., Nicholas, L., Lee, I., Lee, J., \& Scott, D. (2006). Social stratification in recreational Fishing participation: Research and policy implications. Leisure Sciences, 28, 351-368.

Holland, S.M., \& Ditton, R.B. (1992). Fishing trip satisfaction: A typology of anglers. North American Journal of Fishers Management, 12(1), 28-33.

Koupal, K., \& Krasny, M. (2003). Effect of integrating a sportfishing curriculum into a camp program on the knowledge, awareness, and attitudes of participating youth. Journal of Extension, 41(1).

Palmberg, I.E. \& Kuru, J. (2000). Outdoor activities as a basis for environmental responsibility. The Journal of Environmental Education, 31(4), 32-36.

Siemer, W.F. \& Knuth, B.A. (2001). Effects of fishing education programs on anecdotes of responsible environmental behavior. Journal of Environmental Education, 32(4), 23-29.

Spencer, P. (1993). Factors influencing satisfaction of anglers on Lake Miltona, Minnesota. [Abstract]. North American Journal of Fisheries Management, 13(2), 201-209. 
[USDI] U.S. Department of the Interior, Fish and Wildlife Service, and U.S. Department of Commerce, U.S. Census Bureau. (2006). 2006 National Survey of Fishing, Hunting, and WildlifeAssociated Recreation. Publication Number: FHW/06-NAT.

(C) Copyright of Journal of Youth Development Bridging Research and Practice. Content may not be copied or emailed to multiple sites or posted to a listserv without copyright holder's express written permission. However, users may print, download or email articles for individual use. 